\title{
ONLINE TOOL WEAR PREDICTION IN MILLING OPERATION USING FEED MOTOR CURRENT SIGNAL
}

\begin{tabular}{|c|c|}
\hline Abhishek Kumar & $\begin{array}{c}\text { Dr. Sachin Kumar Singh } \\
\text { Department of Mechanical Engineering }\end{array}$ \\
$\begin{array}{c}\text { Indian School of Mines(ISM), Dhanbad, India } \\
\text { Email id: abhishek566@ mece.ism.ac.in } \\
\text { Mob. No: }+918083987255\end{array}$ & $\begin{array}{c}\text { Indian School of Mines(ISM), Dhanbad, India } \\
\text { Email id: sachinsingh47@gmail.com }\end{array}$ \\
\hline
\end{tabular}

\begin{abstract}
-
In the present work, artificial neural network (ANN) and regression analysis are used to predict the real time flank wear of a cutting tool (KC710) in milling operation. The various parameters such as root mean square (RMS) value of the spindle motor current, spindle speed, depth of cut and feed-rate are the inputs to the network, and flank wear is the output. Online data of milling operation is taken for training and testing of the neural networks. Effect of various cutting conditions (speed, depth of cut, feed-rate) on the flank wear has been investigated. The flank wear prediction using the trained network is found to be in better agreement in comparison with the experimentally measured flank wear of the milling tool. The value of co-efficient of determination $\left(\mathbf{R}^{2}\right)$, between the model predictions and the experimentally obtained value are compared. Accuracy of the predicted flank wear using neural network is found to be better than that using regression model.
\end{abstract}

Keywords: Artificial neural network; current sensors; Flank wear (VB); Milling; Regression model.

\section{INTRODUCTION}

Various approaches have been proposed to accomplish tool condition monitoring and a number of these are successfully employed for real application in industry. Real time prediction of tool wear plays a very significant role in automated manufacturing system. Many attempts were made to detect tool wear in real time, but a highly precise and reliable tool condition monitoring system has yet to be developed. Tool wear detection methods can be direct or indirect. Visual inspection, computer vision etc., are the direct methods which can be applied while operation is not in the running mode. Hence the milling operation needs to be stopped for the direct measurement of flank wear. This drawback prevents these methods to be used for automated manufacturing systems. The indirect methods of tool condition monitoring, in which various types of sensors signals (such as acoustic emission, force, torque, thrust, current, power, vibration) correlating to flank wear (VB) have been extensively applied for real time prediction of tool wear [1, 2]. Among the various sensors used, current sensor is considered one of the most effective methods of monitoring tool wear in machining processes [3]. The advantage of using the current sensors, it is freely mounted directly to the external power supply connections. Therefore these sensors do not mess with the machining process and are very much cost effective [4] to apply in real applications. Current sensor signals can be used individually as input information to a tool condition monitoring (TCM) system using ANN model or using any other machine learning method, such as support vector machine. Dornfeld [5] developed a neural network model based combining signals from various types of sensors such as current, acoustic emission and force sensor for monitoring tool wear of a single point turning operation. Yingxue et al. [6] developed a fuzzy neural network based model to integrate the motor current and acoustic emission sensor for estimating the tool wear of a boring operation. Mesina and Langari [7] developed a system based on neuro fuzzy to correlate the sensor readings (force sensors, current sensor and acoustic emission sensors) and the tool condition of a metal cutting operation. Brinksmeier [8] applied sensor to detect eddy current to measure the in-process or ongoing torque, which is very sensitive to tool wear and fracture. Jeong and Cho [9] used cutting torque from the rotating and stationary feed motor current during a milling process to estimate the tool breakage. Oh et al. [10] estimated drilling torque using the RMS current of spindle motor and controlled the drilling torque. Wang et al. [11, 12, and 13] have developed a self organizing map (neural network) and trained in a batch mode after each cutting passes against the flank wear. The network is trained with various relevant features of cutting forces (obtained from a sensor based analysis) and measured the degree of wear (obtained from vision based measurement). Jemielniak et al. [14] has studied the various signals for vibration, force, and acoustic emission while turning a specific material and extracted some basic features from the different domains such as frequency, time, and time frequency domains of the signals to detect the wear of the tool. Karali Patra [15] has developed artificial neural network based prediction using the motor current signals of drill flank wear. So far very few attempts have been made to generate the online tool wear condition monitoring system using the spindle motor current signal especially in milling machine. In the present work, the feed motor current signal is used to generate a model based on artificial neural network which can be used to predict the tool wear of the milling tool on predetermined cutting conditions using the input current signal and its accuracy is compared with the regression model. 


\section{O \\ ELK \\ Asia Pacific Journals}

\section{SETUP AND OPERATIONS}

Experimental data has been taken from Kai Goebel, (NASA Ames) \& Alice Agogino, (UC Berkeley) [16]. The basic setup of the milling machine consist the spindle and the table of the Matsuura machining center MC-510V. A OMRON K3TBA1015 current converter, powered by HP 6237B triple output power supply providing $15 \mathrm{~V}$, feeds the signal from one spindle motor current phase into the cable connector. A model CTA 213 current sensor which uses the same phase of the spindle motor current is fed into the cable connector. The signal from a spindle motor current sensor is fed directly without further processing into the computer to store the data. Recorded data further processed for artificial neural network and regression analysis.

Table 1: Experimental milling condition data set

\begin{tabular}{|l|l|l|l|l|}
\hline $\begin{array}{l}\text { Milling } \\
\text { condi-tion }\end{array}$ & $\begin{array}{l}\text { Number of } \\
\text { Runs }\end{array}$ & $\begin{array}{l}\text { Feed rate, } \\
\mathrm{mm} / \text { rev }\end{array}$ & $\begin{array}{l}\text { Depth of } \\
\text { cut }(\mathrm{mm})\end{array}$ & $\begin{array}{l}\text { Speed, } \\
\text { rev/min }\end{array}$ \\
\hline Case 1 & 13 & 0.75 & 0.50 & 826 \\
\hline Case 2 & 14 & 0.75 & 0.25 & 826 \\
\hline Case 3 & 20 & 1.50 & 0.50 & 826 \\
\hline
\end{tabular}

There are 3 cases with varying number of runs as shown in the Table 1. The number of runs depends on the degree of flank wear, measured between runs at irregular intervals up to a wear limit (and sometimes beyond). The matrix for the parameters chosen for the experiments were guided by keeping in mind the industrial applicability and recommended manufacturer's settings. Therefore, the cutting speed was constant for all three cases at $200 \mathrm{~m} / \mathrm{min}$ which is equivalent to $826 \mathrm{rev} / \mathrm{min}$. Two different depths of cut were chosen, $1.5 \mathrm{~mm}$ and $0.75 \mathrm{~mm}$. Also, two feeds were taken, $0.5 \mathrm{~mm} / \mathrm{rev}$ and $0.25 \mathrm{~mm} / \mathrm{rev}$ which translate into $413 \mathrm{~mm} / \mathrm{min}$ and $206.5 \mathrm{~mm} / \mathrm{min}$, respectively. The tool insert is coated with multiple layers of titanium carbide, titanium carbon nitride and titanium nitride in sequence for milling on a cast iron work piece. All experiments were repeated a second time with the identical parameters with another set of identical inserts. The size of the work pieces was $483 \mathrm{~mm} \times 178 \mathrm{~mm} \times 51 \mathrm{~mm}$.

Tool wear: A high quality product often implies high quality surface finish and dimensional accuracy in production. Ideally, a sharp tool has to be maintained at all times. A rough tool deforms the surface very often with high impact. A dull one may tear the surface which in result may lower the fatigue resistance of the tool. A damaged tool also results in high friction which leads to the higher cutting temperatures at the tip of the tool. Unwanted effects may arise from these temperatures. So, the wear of the tool has to be controlled and it should be the minimum. There are many parameters which affect the wear and the life of the tool (such as depth of cut, feed rate, cutting speed and type of material etc). In this work, the flank wear VB is used as a parameter for analyzing tool wear. The flank wear VB is measured as the distance from the cutting edge of the tool to the end of the abrasive wear on the

\section{ELK Asia Pacific Journals - Special Issue}

ISBN: 978-81-930411-8-5

flank face of the milling tool. The insert was taken out of the tool and the flank wear was measured with the help of a microscope during each experiment.

\section{ARTIFICIAL NEURAL NETWORK}

Training plays a significant role in designing an ANN network. The accuracy of the ANN model for better prediction depends on the training of the network and also depends on the various input/output data conditions. The training conditions are shown in the table 2. The network is based upon two phases of data flow. In the first phase, the input information is propagated from the input layer, with five input neuron, to the output layer through the three hidden neurons. It produces an output with error signal. Then the error signal analyzes the ANN model from the difference between the model predicted values with the measured value. These signals are then back propagated from the output layer as a feedback to the previous layers. These signals are used to update their weights respectively and the update of weights continues till the network attains the required error limit. Initially, the number of neurons in the hidden layer is chosen to be three. Thereafter, number of neurons is added incrementally to the hidden until a significant progress is not observed in performance of the network. The performance (or average error) of the neural network model are evaluated by mean squared error (MSE) between the actual measured value and the model predicted values of tool wear. When the performance of the network reaches the required goal, it is necessary to stop the training of the neural network and it is ready to be verified for new data set. Different ANN model are generated for the three cases (table 2) and the model is tested with new data set.

\section{Table 2}

\section{SUMMARY OF ANN MODEL}

Object model: prediction of flank wear, VB

Input neuron: $\mathrm{V}$, f, d, variance, kurtosis

Output neuron: flank wear(VB)

Network structure

Network type: Feed-forward back propagation

Transfer function: Tansig/ Purelin

Training function: Trainlm

Learning function: Learngdm

\section{Learning conditions}

Learning scheme: Supervised learning

Learning rule: Gradient descent rule

Input neuron: Five

Output neuron: One

Sample pattern vector: 10 (for training), 4 (for testing)

Number of hidden layer: 1 (one)

Neurons in hidden layer: 3

Learning rate, $\alpha$ : 0.1

Momentum constant, $\beta: 0.5$

Performance goal/Error goal: 0.0001

Maximum epochs (cycles) set: 10,000

MSE at the end of training: 6.1746e-05 
ELK

Asia Pacific Journals

Performance Evaluation of the Designed Neural Network

Training and testing performance of the optimum network Architecture can be evaluated by the following measures:

$O_{j}^{i}=A * T_{j}+B$

MAPE $=\left\{\frac{\left(T_{j}-o_{j}\right)}{T_{j}}\right\} * 100$

$M S E=\left\{\frac{1}{n} \sum_{j}\left(T_{j}-O_{j}\right)^{2}\right\}$

$R^{2}=1-\left(\frac{\Sigma_{j}\left(T_{j}-o_{j}\right)^{2}}{\sum_{j}\left(T_{j}\right)^{2}}\right)$

Where, O: predicted flank wear/Output (mm)

A, B: constant, varies between 0 and 1

$\mathrm{T}$ : actual/ measured flank wear as target

$\mathrm{j}$ : Processing elements

i: Case number

n: Number of patterns

MAPE: Mean average percentage of error

MSE: Mean squared error

$\mathrm{R}^{2}=$ Coefficient of determination

\section{REGRESSION MODEL}

Using the Regression analysis is a very common in statistical process of estimating the relationships among the several variables. It includes a number of techniques for analyzing and modeling the variables, when the focus is to build a relationship between the dependent and independent variables. The regression model is generated in Matlab. Considering coefficient of determination and mean average percentage error, the best suitable regression model is obtained using third-degree polynomial equations. The resulting regression model is given in Eqns. (1-3)

$O_{j}^{i}=\left(P_{1} * I^{3}\right)+\left(P_{2} * I^{2}\right)+\left(P_{3} * I\right)+P_{4}$

$R^{2}=\frac{\sum_{j=1}^{n}\left(T_{j}-o_{j}\right)^{2}}{\sum_{j=1}^{n}\left(T_{j}-o_{m}\right)^{2}}$

MAPE $=\left\{\frac{\left(T_{j}-o_{j}\right)}{T_{j}}\right\} * 100$
ELK Asia Pacific Journals - Special Issue

ISBN: 978-81-930411-8-5

Where, O: predicted flank wear ( $\mathrm{mm})$

$\mathrm{P}_{1}, \mathrm{P}_{2}, \mathrm{P}_{3}$, and $\mathrm{P}_{4}$ : slope and Intercept

I: DC current value

j: Processing elements

i: Case number

$\mathrm{O}_{\mathrm{m}}$ : Mean of predicted flank wear

$\mathrm{T}$ : actual/ measured flank wear as target.

$\mathrm{R}^{2}=$ Coefficient of determination

This equation was auto generated with Matlab which can be used to predict the tool wear. A single class regression model was generated for this task. DC current signal were given as input, actual flank wear were given as target to generate the Regression model. To test the model accuracy, new data set of DC current is used as input to predict the flank wear.

\section{RESULTS AND DISCUSSION}

All three cases with different runs are modeled to predict real time flank wear VB of the milling tool. Both Regression and ANN model are generated on Matlab and the results are stored for future use. The feed motor current for different run of case 2 (Table 1) is shown in Figure 1. It can be observed from Figure 1 that the current consumption increases with flank wear also. It shows strong relationship between flank wear and DC current. Therefore the current signals can be used as input to the neural network with other parameter such as kurtosis; variance and the actual flank wear as a target to the ANN and Regression model.

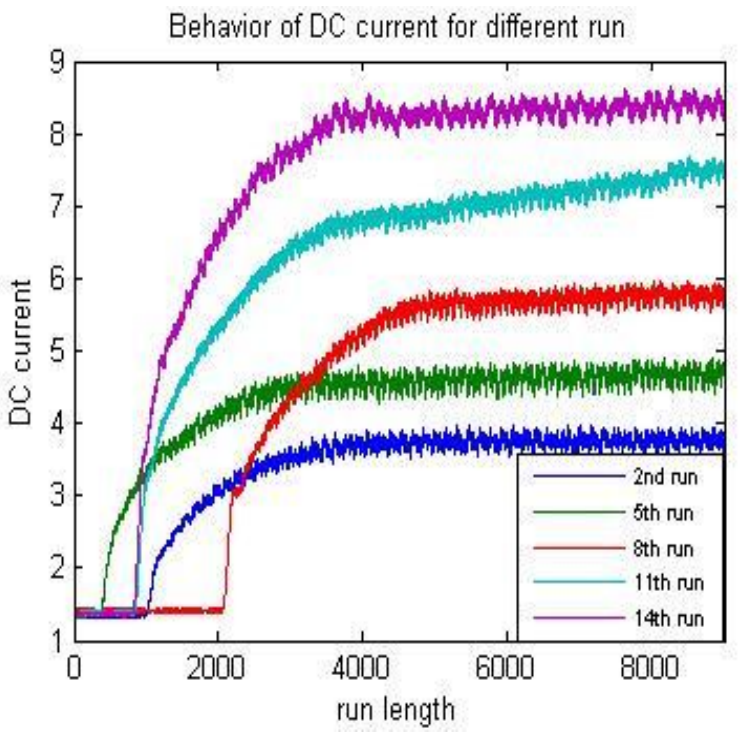

DC current consumption rate for different run (case 2).
Fig.1: 
ELK

Asia Pacific Journals

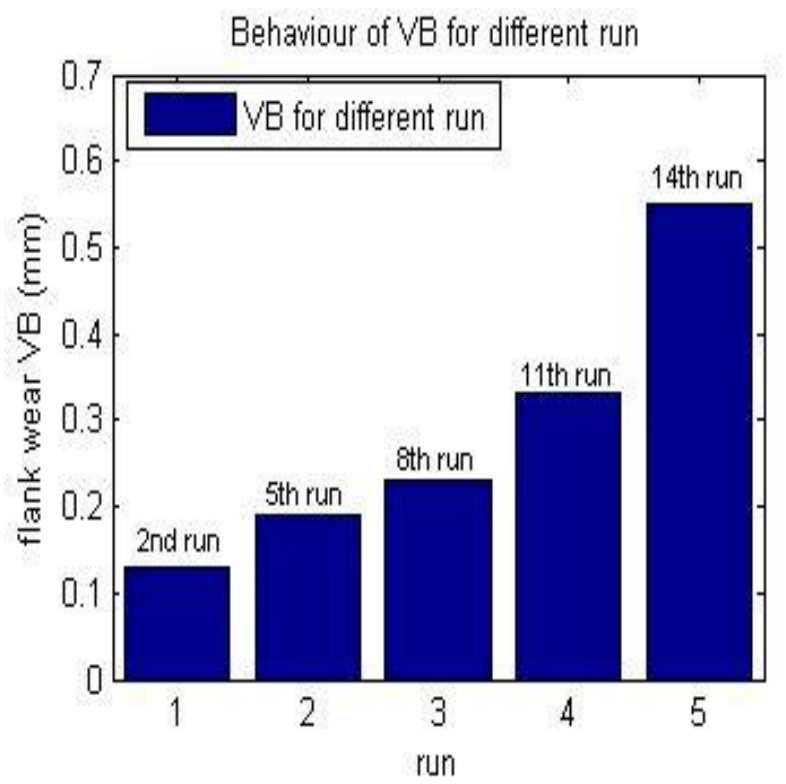

Fig.2: flank wear of different run (case 2).

The values of coefficient of determination (R) and the output equation (to calculate output) for ANN model were generated for all three cases shown in figure 3 respectively.

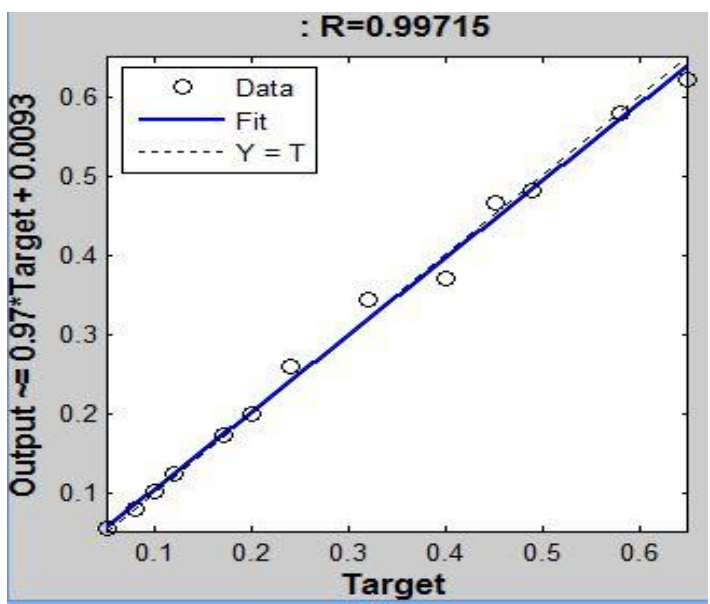

Fig.3a: Actual (target) flank wear Vs predicted (output) flank wear for case 1 .

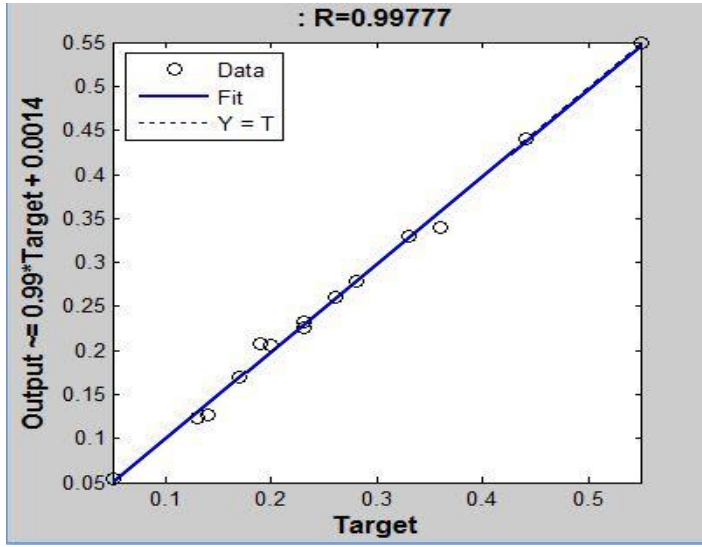

Fig.3b: Actual (target) flank wear Vs predicted (output) flank wear for case 2 .

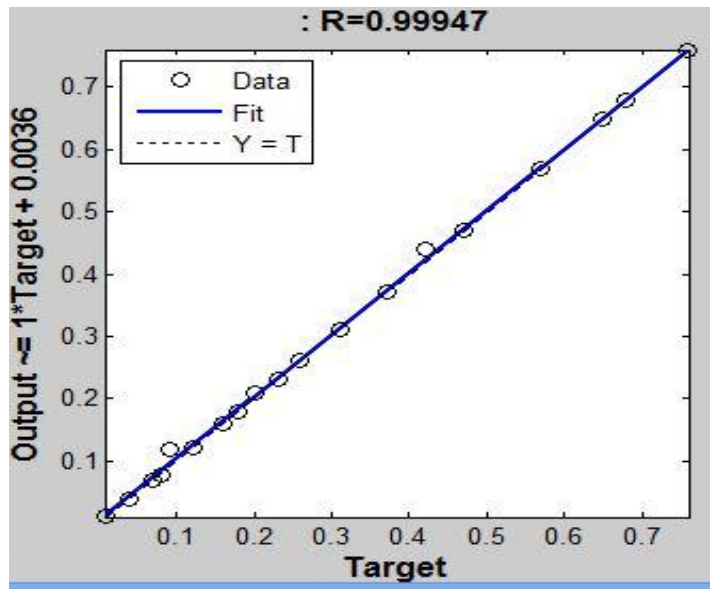

Fig.3c: Actual (target) flank wear Vs predicted (output) flank wear with corresponding R values by ANN (for case 1,2 and 3).

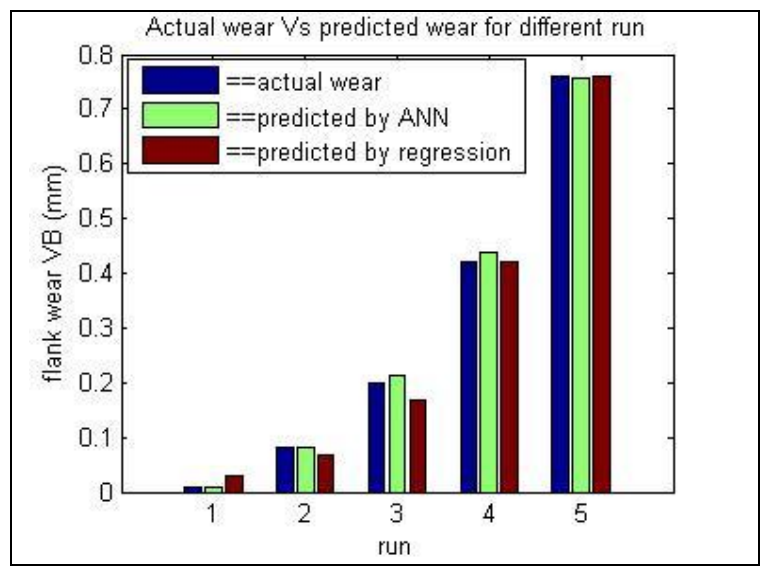

Table 4: Model performance table (ANN Vs Regression) 
ELK

Asia Pacific Journals
ELK Asia Pacific Journals - Special Issue

ISBN: 978-81-930411-8-5

\section{Acknowledgements}

\begin{tabular}{|c|c|c|c|}
\hline $\begin{array}{l}\text { Performa-nce } \\
\text { parameter }\end{array}$ & $\mathbf{R}$ & MSE & $\begin{array}{c}\text { MAPE } \\
(\%)\end{array}$ \\
\hline \multicolumn{4}{|l|}{ Case 1} \\
\hline ANN & 0.9971 & $2.36 \mathrm{e}-4$ & 3.168 \\
\hline Regression & 0.9954 & $7.61 \mathrm{e}-4$ & 7.077 \\
\hline \multicolumn{4}{|l|}{2 Case 2} \\
\hline ANN & 0.9977 & $7.29 \mathrm{e}-5$ & 3.057 \\
\hline Regression & 0.9910 & $1.45 \mathrm{e}-4$ & 6.735 \\
\hline \multicolumn{4}{|l|}{ Case 3} \\
\hline ANN & 0.9995 & $6.17 \mathrm{e}-5$ & 2.136 \\
\hline Regression & 0.9795 & $4.10 \mathrm{e}-2$ & 6.667 \\
\hline
\end{tabular}

Fig.4 Actual flank wear (VB) Vs predicted VB for case 3.

The fig.4 represents the comparison of flank wear VB prediction by the two models, the Artificial Neural Network and the regression model. The best mean average percentage error (MAPE) with ANN model is $2.136 \%$ and the coefficient of determination $(\mathrm{R})$ is 0.9995 with the performance of $6.17 \mathrm{e}$ 05 in the case 3 as shown in table 3 . The network performance result is shown in the table 3 . It can be observed from Table 3 that performance of ANN is better than the performance of regression model in all cases.

\section{CONCLUSIONS}

The effects of flank wear and milling conditions on the spindle motor current are investigated. Flank wear is correlated to the feed current by a multilayer neural network over a range of cutting conditions. It has been noted that as the rate of flank wear increases the rate of current consumption also increases. The performances and the mean average percentage error (MAPE) of different neural network based model have been studied. The trained model of neural network based on the current sensor signals from the spindle motor has very accurately predicted the flank wear for the different set of combination of tool work piece materials for different range of various cutting conditions. Also, it is observed that he performance of ANN is better than the performance of regression model for the prediction of flank wear using feed motor current signal. The minimum and maximum average error predicted by ANN is $2.136 \%$ and $3.168 \%$, respectively. The estimated results predicted with ANN are very accurate and encouraging to be applied in automated industry for real application.
This research work was financially supported by Science \& Engineering Research Board, India

File no. YES/2015/001555, In addition, the experimental data (mill data set) were obtained from NASA [16] Data repository, contributed by Professor Kai Goebel, (NASA Ames) \& Alice Agogino, (UC Berkeley).

\section{References}

[1] L. Dan, J. Mathew, Tool wear and failure monitoring techniques for turning a review, Int. J. Mach Tools Manuf. 30 (4) (1990) 579-598.

[2] E. Jantunen, A summary of methods applied to tool condition monitoring in drilling, Int. J. Mach. Tools Manuf.42 (2002) 997-1010.

[3] M.A. Mannan, S Broms, Monitoring and adaptive control of cutting process by means of motor power and current measurements, Ann. CIRP 38 (1) (1989) $347-$ 350 .

[4] G. Byrne, D. Dorfeld, I. Inasaki, G. Ketteler, W. Konig, R Teti, Tool condition monitoring (TCM) the status of research and industrial application, Ann. CIRP 44 (2) (1995) 541-567.

5] D. A. Dornfeld, Neural network sensor fusion for tool condition monitoring, Ann. CIRP 39 (1), (1990) 101-105.

[6] Y. Yingxue, L. Xiaoli, Y. Zhejun, Tool wear detection with fuzzy classification and wavelet fuzzy neural network, Int. J. Mach. Tools Manuf. 39 (1999) 15251538.

[7] O.S. Mesina, R. Langari, A neuro-fuzzy system for tool condition monitoring in metal cutting, Trans. ASME J. Eng. Ind. 123 (2001) 312-318.

[8] E. Brinksmeier, Prediction of tool fracture in drilling, Ann. CIRP 39 (1) (1990) $97-100$.

[9] Y.H. Jeong, D.W. Cho, Estimating cutting force from rotating and stationary feed motor currents on a milling machine, Int. J. Mach. Tools Manuf. 42 (2002) $1559-1566$.

[10] Y.T. Oh, W.T. Kwon, C.N. Chu, Drilling torque control using spindle motor current and its effect on tool wear, Int. J. Adv. Manuf. Technol. 24 (2004) 327-334. [11] Wang, W. H., Hong, G. S, Wong, Y. S., \& Zhu, K. P. (2007), Sensor fusion for online tool condition monitoring in milling, International Journal of Production Research, 45, 5095-5116, Cross Ref http://dx.doi.org/10.1080/00207540 500536913.

[12] Wang, G., Qian, L., \& Guo, Z. (2013a). Continuous tool wear prediction based on Gaussian mixture regression model. The International Journal of Advanced Manufacturing Technology, 66, 1921-1929. Cross Ref (http://dx.doi.org/10.1007/s00170012 4470z).

[13] Wang, G., \& Cui, Y. (2013b). On line tool wear monitoring based on auto associative NN. Journal of Intelligent Manufacturing 24, 10851094, Cross Ref (http://dx.doi.org/ 10.1007/s1084501206367)

[14] Jemielniak, K., Urbanski, T., Kossakowska, J., \& Bombinski, S. (2012). Tool condition monitoring based on numerous signal features. The International Journal of Advanced Manufacturing Technology, 59, 73-81.CrossRef (http://dx.doi.org/10.1007/s0017001135042

[15] Karali Patra, Surjya K. Pal \& Kingshook Bhattacharyya, Artificial neural network based prediction of drill flank wear from motor current signals Applied Soft Computing 7 (2007) 929-935.

[16] Kai Goebel, (NASA Ames) \& Alice Agogino, (UC Berkeley) http://ti.arc.nasa.gov/ tech/ dash/pcoe/prognostic-data-repository/ 